\title{
Factors Affecting the Harmonics Generated by a Group of CFLs: Experimental Measurements
}

\author{
Muhyaddin J. H. Rawa, David W. P. Thomas \\ Electrical Systems and Optics Research Division, the University of Nottingham, Nottingham, NG7 2RD, UK
}

Email address:

mrawa@kau.edu.sa (Muhyaddin J. H. R.), dave.thomas@nottingham.ac.uk (David W. P. T.)

To cite this article:

Muhyaddin J. H. Rawa, David W. P. Thomas. Factors Affecting the Harmonics Generated by a Group of CFLs: Experimental Measurements. American Journal of Electrical Power and Energy Systems. Vol. 4, No. 1, 2015, pp. 10-16. doi: 10.11648/j.epes.20150401.12

\begin{abstract}
The penetration of nonlinear loads on power systems increases the harmonics that can cause detrimental problems to power systems such as an increase in voltage distortion, equipment failure, system resonance, increase system losses and decrease system efficiency. Many factors affect the harmonics produced by nonlinear loads. Hence, the aim of this paper is to evaluate the impacts of system voltage, impedance, frequency and background voltage distortion on the harmonics generated by a group of Compact Fluorescent Lamps (CFLs). Experimental measurements are performed for this purpose.
\end{abstract}

Keywords: Distortion, Harmonics, Power Quality, CFLs, Nonlinear Loads, THD

\section{Introduction}

Recently, due to the widespread use of power electronics based nonlinear loads and equipment, distortion levels in power systems are increased. It has been estimated that by $2012,60 \%$ of the loads on power systems will be nonlinear [1]. The proliferation of nonlinear loads increases the harmonic level in power system networks and can cause severe problems such as an increase in voltage distortion, system resonance, a decrease in Power Factor (PF), increase system losses, equipment failure, thermal effects on rotating machines and decrease in the overall system efficiency [2-7].

Lighting forms one of the most important loads in power systems. According to [8], about $25 \%-35 \%$ of the global generated power is consumed by lighting. Another study claims that lighting energy constitutes $15 \%$ of the total energy in residential buildings and 30\% in commercial buildings [5].

Due to the advance in power electronics technology, Fluorescent Lamps (FLs) and Compact Fluorescent Lamps (CFLs) are becoming increasingly more popular for many reasons. First, the efficiency of FLs is three to four times the efficiency of Incandescent Lamps (ILs) for the same light output. FLs efficiency can also be improved by $20 \%-30 \%$ using a higher switching frequency $(>25 \mathrm{kHz})[5,9]$. Second, lifetime of a typical CFL is two to three times that of an IL.

FLs and CFLs are discharge lamps; hence, they require a ballast to establish a high initial voltage across the lamp tube for proper lamp ignition and to limit the lamp current once the arc is established $[5,6,9]$. There are electronic ballasts and magnetic ballasts. Magnetic ballasts use iron-core transformers for stable operation; however, this might cause extra heat losses across the ballast $[5,9]$. These transformers also make magnetic ballasts bulky and heavy. Magnetic ballasts operate at a line frequency of 50 or $60 \mathrm{~Hz}$, which cause light flickering. Magnetic ballasts need a pre-heat or switch start circuit to heat up the tube to form the required arc across fluorescent tubes. A standard magnetic ballast current distortion is $15 \%$ [6]. Typically, lifetime of electronic ballasts is less than 8 years, while lifetime of magnetic ballasts is more than 30 years [10]. Magnetic ballasts will be phased out from the United Kingdom market by 2017 because their efficiencies are much lower than those of electronic ballasts [11].

Electronic ballasts use SMPSs to convert the power frequency to a very high switching frequency in the range of 25 to $40 \mathrm{kHz}$ [5]. Due to the fact that Electronic ballasts employ SMPSs, their current distortion could be as high as $100 \%$ or even more [12-15]. Electromagnetic Interference (EMI) filters are used to minimize the high frequency conducted noise $[5,6]$. In order to minimize their cost and size, most of the commercial CFLs nowadays do not include Power Factor Correction (PFC) circuit [9]. Hence, a typical FL with electronic ballast has a power factor of $0.6[12,15]$.

A number of studies have been conducted to investigate the factors that can affect the harmonics produced by nonlinear loads. In [16-22], attenuation, which refers to the interaction of voltage and current distortions due to shared system impedance, and diversity, which refers to the partial 
cancellation of harmonic currents due to phase angle diversity, are discussed. The effects of mixing single and three phase non-linear loads on harmonic cancellation are also quantified in [23]. Harmonic cancellation due to different single-phase nonlinear loads is illustrated in [24].

The influence of supply voltage distortion on the harmonic currents of a single-phase diode bridge rectifier is discussed in [25]. Effects of voltage distortion on the harmonics generated by household appliances are described in [26-29]. However, all previously mentioned experimental studies have not employed purely sinusoidal power supplies. Hence, harmonics quantification due to a particular factor is not fully assessed.

Notwithstanding, authors in [30] discuss the effects of voltage, impedance and frequency variations on the harmonics generated from a single Personal Computer (PC). The impact of linear loads on the harmonics generated from nonlinear loads is described in [31]. Different factors that can affect the harmonics generated by a cluster of PCs are discussed in [32, 33] including system voltage, impedance, frequency, background voltage distortion, percentage of linear loads, attenuation and diversity effects.

This paper aims to investigate the effects of source voltage, frequency, impedance and background voltage distortion on the harmonics generated by a group of CFLs. One of the key objectives of this research study is to evaluate experimentally the effects of different factors individually and precisely. This is achieved by controlling the input voltage magnitude, frequency, source impedance and background distortion using a programmable AC source Chroma ${ }^{\mathrm{TM}} 61511$ [34]. The Chroma helps in isolating the test rig and filtering out harmonics and fluctuations from the mains. Also, a high accuracy KinetiQ PPA1530 Power Analyzer was used to monitor the input voltage and current of the device under test [35].

Due to the fact that the current drawn by a single CFL is too small, its voltage distortion is almost negligible. Therefore, variation in source voltage, frequency or impedance has a minor effect on voltage distortion. Hence, only current distortion is considered. However, the background voltage distortion affects voltage harmonics notably. Therefore, both $\mathrm{THD}_{\mathrm{i}}$ and $\mathrm{THD}_{\mathrm{v}}$ were evaluated.

Voltage, impedance, frequency and background voltage distortion variations are within the permissible limits according to BS 7671, IEEE 519, for National Grid and Central Networks in the UK [36-39]. One parameter was changed at a time while the other factors were kept constant at nominal values. Nominal values for the system were set to be $240 \mathrm{~V}, 50 \mathrm{~Hz}, 0.25 \Omega$ and zero background voltage distortion (a pure sine wave voltage source).

The paper is organized as follows: section II presents harmonic indices calculations based on IEEE 1459 [40]. Section III discusses the CFL Model. The factors that can affect the harmonics generated from the CFLs are introduced in section IV. Finally, Section V presents the summary and conclusions.

\section{Harmonic Indices Calculations}

The most commonly used harmonic quantification indices are the Voltage and Current Total Harmonic Distortion $\left(\mathrm{THD}_{\mathrm{v}}\right.$ and $\mathrm{THD}_{\mathrm{i}}$ ) [40].

The RMS voltage and current are [40]:

$$
\begin{gathered}
V_{H}^{2}=V^{2}-V_{1}^{2} \\
I_{H}^{2}=I^{2}-I_{1}^{2}
\end{gathered}
$$

Voltage and current total harmonic distortion can be calculated as follows [40].

$$
\begin{aligned}
& T H D_{v}=\frac{V_{H}}{V_{1}}=\sqrt{\left(\frac{V}{V_{1}}\right)^{2}-1} \\
& T H D_{I}=\frac{I_{H}}{I_{1}}=\sqrt{\left(\frac{I}{I_{1}}\right)^{2}-1}
\end{aligned}
$$

where

$\mathrm{V}, \mathrm{V}_{1}$ and $\mathrm{V}_{\mathrm{H}}$ : total, fundamental and harmonic voltages, $\mathrm{V}$ I, $\mathrm{I}_{1}$ and $\mathrm{I}_{\mathrm{H}}$ : total, fundamental and harmonic currents, A

\section{CFL Model}

In general, a CFL consists of four main block diagrams, the EMI filter, rectifier, resonant inverter stage with its control system and lamp [8, 9, 12, 41-43]. According to [5], EMI filters provide large attenuation for high switching noise currents that are generated due to the rapid changes of $\mathrm{di} / \mathrm{dt}$ and $\mathrm{dv} / \mathrm{dt}$ at high switching frequency. The rectifier transforms the $50 \mathrm{~Hz}$ ac voltage into a dc. The function of the resonant inverter is to convert the dc voltage to an ac voltage at a very high switching frequency suitable to drive the lamp. The harmonics generated by the CFLs are mainly caused by the $\mathrm{ac} / \mathrm{dc}$ and $\mathrm{dc} / \mathrm{ac}$ converters.

\section{Factors Affecting the Generated Harmonics}

In this section, different factors that may affect the harmonics generated by a cluster of CFLs are introduced through laboratory measurements.

\subsection{Supply Voltage Variation}

Supply voltages in power system can vary within prescribed limits. In order to evaluate the impact of voltage variation on the harmonics produced by a group of CFLs, the input voltage varies from $228 \mathrm{~V}$ to $252 \mathrm{~V}, \pm 5 \%$ on a $240 \mathrm{~V}$ supply. It can be shown from Figure 1 that increasing supply voltage increases $\mathrm{THD}_{\mathrm{i}}$. 


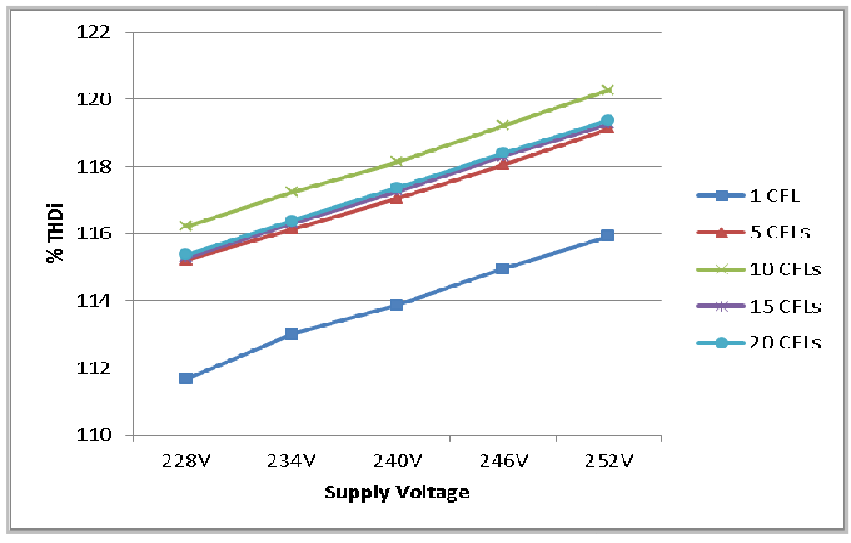

Figure 1. $T H D_{i}$ vs. supply voltage variation

Figure 1 also shows that all curves have the same slope; therefore, the same percentage effect due to the supply voltage changes.

\subsection{Source Impedance Magnitude and X/R Ratio Variations}

Cable length and system loading affect source impedance magnitude and $\mathrm{X} / \mathrm{R}$ ratio. Figure 2 illustrates that for a group of up to 20 CFLs supplied through a wide range of system impedance magnitudes, increasing the source impedance has almost no impact on the harmonics generated from the CFLs. In this case, the system impedance magnitude varies from $0.15 \Omega$ to $0.95 \Omega$ while the $\mathrm{X} / \mathrm{R}$ ratio is $15^{\circ}$.

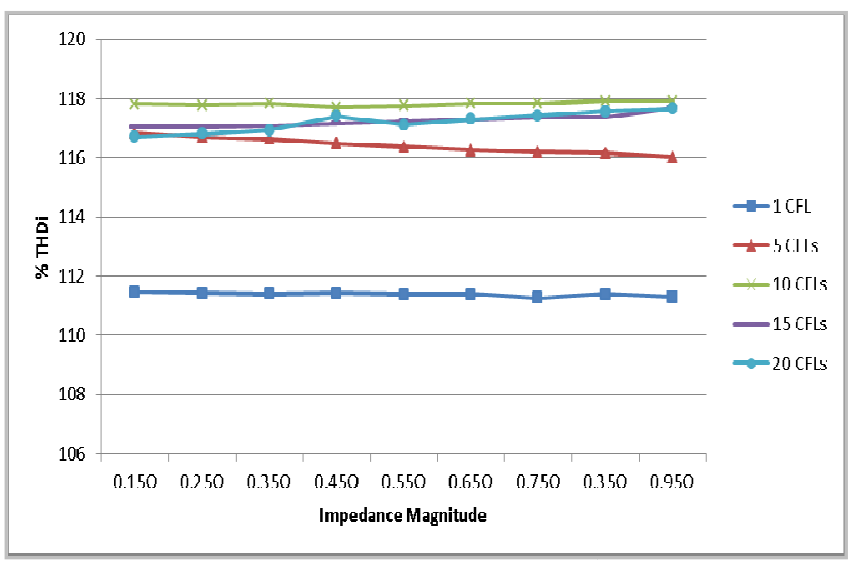

Figure 2. $T H D_{i}$ vs. source impedance magnitude variation

$\mathrm{X} / \mathrm{R}$ ratio in power networks is quite high. This is because the impedance of the generation and transmission equipment is mainly inductive. However, as cable sizes inside commercial offices and residential buildings are of small sizes, their $\mathrm{X} / \mathrm{R}$ ratios are lower. Therefore, the source impedance seen by commercial and residential loads towards the source varies depending on their location within the building. Figure 3 proves that for a single $\mathrm{CFL}$, increasing $\mathrm{X} / \mathrm{R}$ ratio has almost no effect on the generated harmonics. However, when a group of 5 or more CFLs is considered, THD $_{\mathrm{i}}$ increases with increasing the $\mathrm{X} / \mathrm{R}$ ratio.

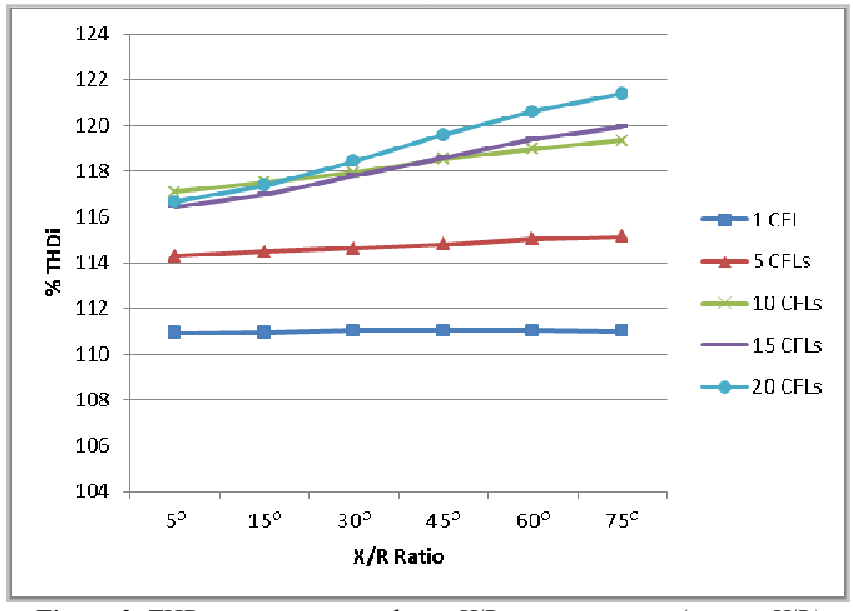

Figure 3. $T H D_{i}$ vs. source impedance $X / R$ ratio variation (arc tan $X / R$ )

In this case, the system impedance $\mathrm{X} / \mathrm{R}$ ratio varies from $5^{\circ}$ to $75^{\circ}$ while the impedance magnitude is set to be $0.25 \Omega$.

\subsection{System Frequency Variation}

System frequency can change due to faults on bulk transmission systems or the disconnection of large loads [6]. When a group of up to 20 CFLs are connected simultaneously to a single supply, changing the system frequency from $49.5 \mathrm{~Hz}$ to $50.5 \mathrm{~Hz}$ has very minor impact on the generated harmonic currents as seen in Figure 4.

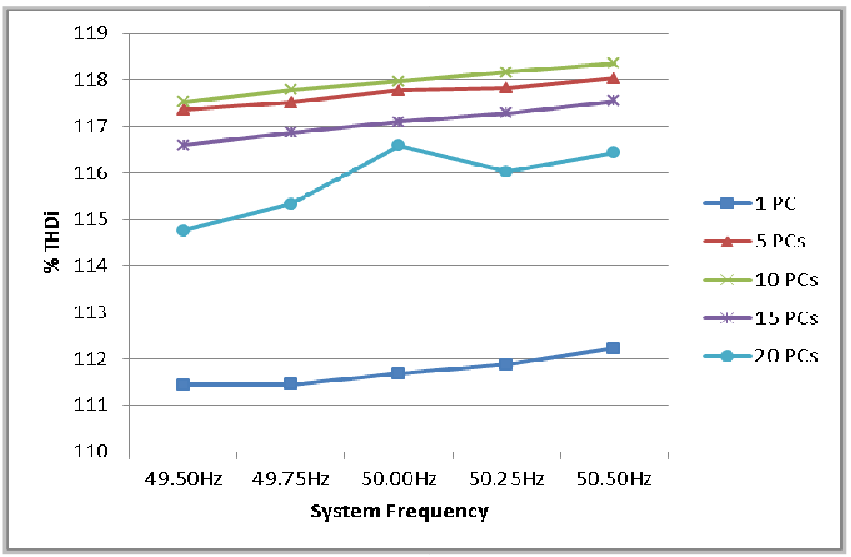

Figure 4. $T H D_{i}$ vs. system frequency variation

\subsection{Background Voltage Distortion Variation}

Due to the ever increasing number of nonlinear loads in power systems, source voltages are becoming more distorted. Figure 5 shows the impact of background voltage distortion on the harmonics generated from CFLs. It can be shown from the Figure that increasing the background voltage distortion within the IEEE recommended limits [36] increases current distortion notably. For example, for a group of 20 CFLs increasing the voltage distortion from $0 \%$ (sinusoidal waveform) to $5 \%$ increases $\mathrm{THD}_{\mathrm{i}}$ from 117.4 to $125.9 \%$. 


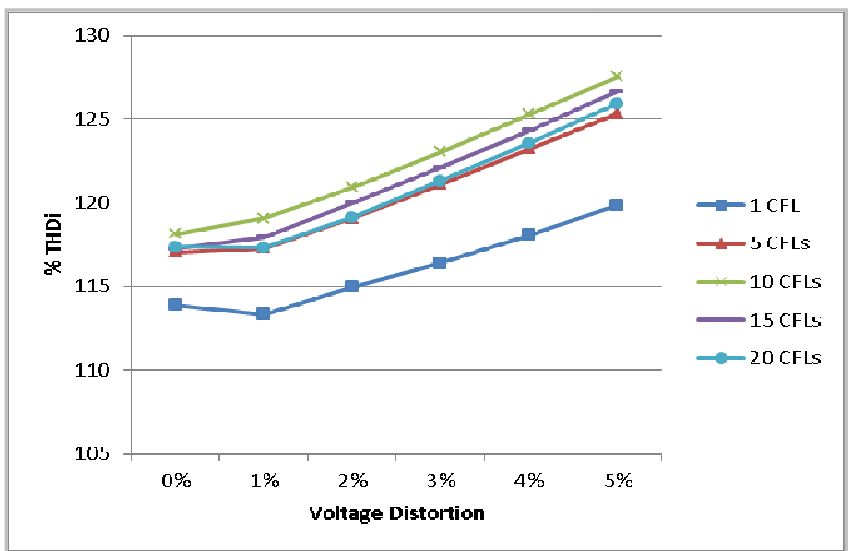

Figure 5. $T H D_{i}$ vs. background voltage distortion variation

In power system analysis, it is very important to assess the harmonics penetration and their impact on the networks and customers. For this reason IEEE 519 not only recommends the $\mathrm{THD}_{\mathrm{i}}$ limits, but also set maximum permissible limits for individual harmonics. For this purpose, assessing the effects of background voltage distortion on individual harmonics is important.

Figure 6 shows that increasing voltage distortion to $5 \%$ decreases the magnitudes of the $3^{\text {rd }}$ harmonic currents. The percentage decrements tend to be more when more CFLs are considered.

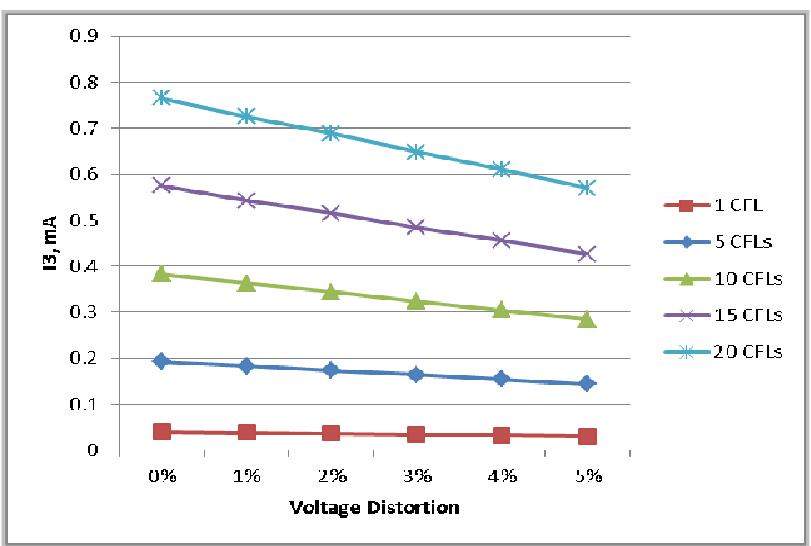

Figure 6. $3^{\text {rd }}$ harmonic currents vs. background voltage distortion variation

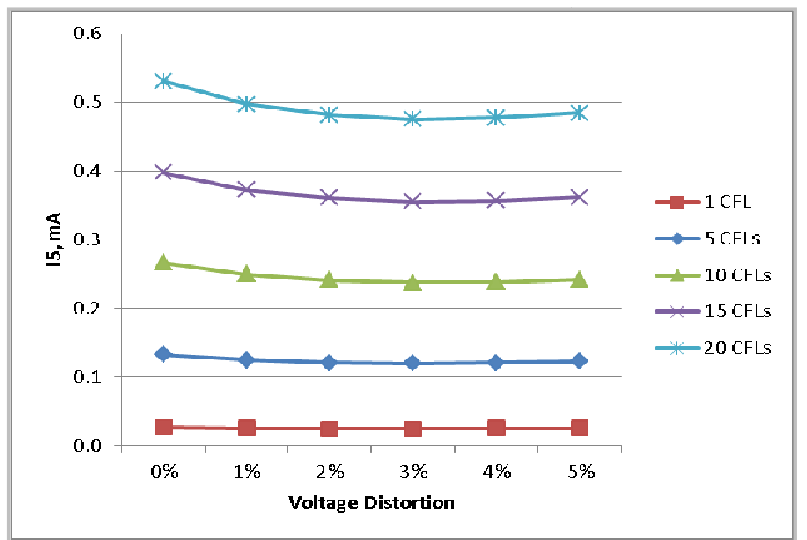

Figure $7.5^{\text {th }}$ harmonic currents vs. background voltage distortion variation
Increasing the background voltage distortion has a minor impact on the $5^{\text {th }}$ harmonic currents when a cluster of 10 or more CFLs are turned on simultaneously as shown in Figure 7. Notwithstanding, it has no effect when 5 or less CFLs are considered.

However, increasing the background voltage distortion from 0 to $5 \%$ increases the $7^{\text {th }}$ harmonic currents as shown in Figure 8 .

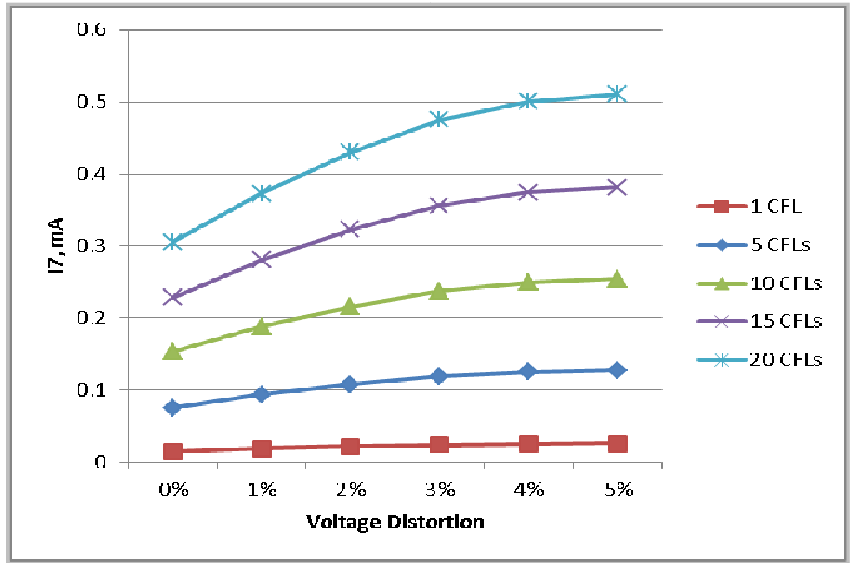

Figure 8. $7^{\text {th }}$ harmonic currents vs. background voltage distortion variation

As the background voltage distortion increases from 0 to $5 \%, \mathrm{THD}_{\mathrm{v}}$ and individual harmonic voltages increase sharply as shown in Figures 9 to 12 .

As the background voltage distortion is mainly produced by the Chroma power supply and the voltage distortion caused by the CFLs are very small compared to the former, the curves shown if Figure 9 are almost identical. The same is also true for all curves of Figures 10 to 12.

It should be noted that the different background voltage distortion levels were obtained by adding individual voltage harmonic sources in series with the $50 \mathrm{~Hz}$ fundamental voltage source which distorts the supply voltage. The Chroma power supply can be programmed to give voltage distortion up to $5 \%$.

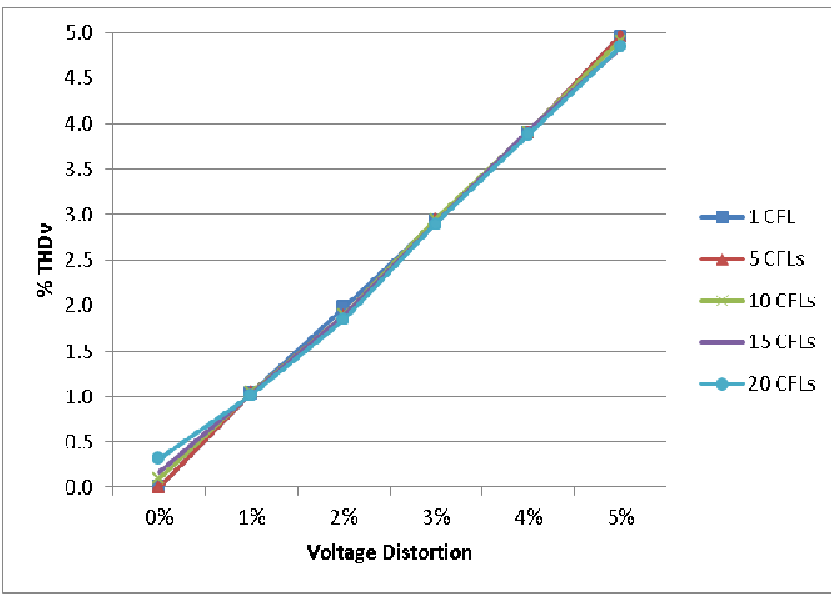

Figure 9. $T H D_{v}$ vs. background voltage distortion variation 


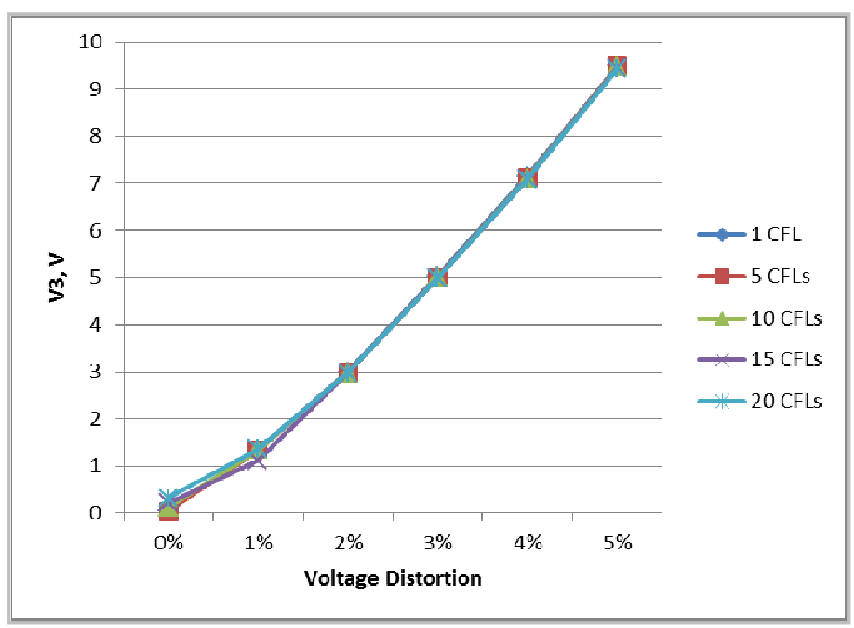

Figure 10. $3^{\text {rd }}$ harmonic voltages vs. background voltage distortion variation

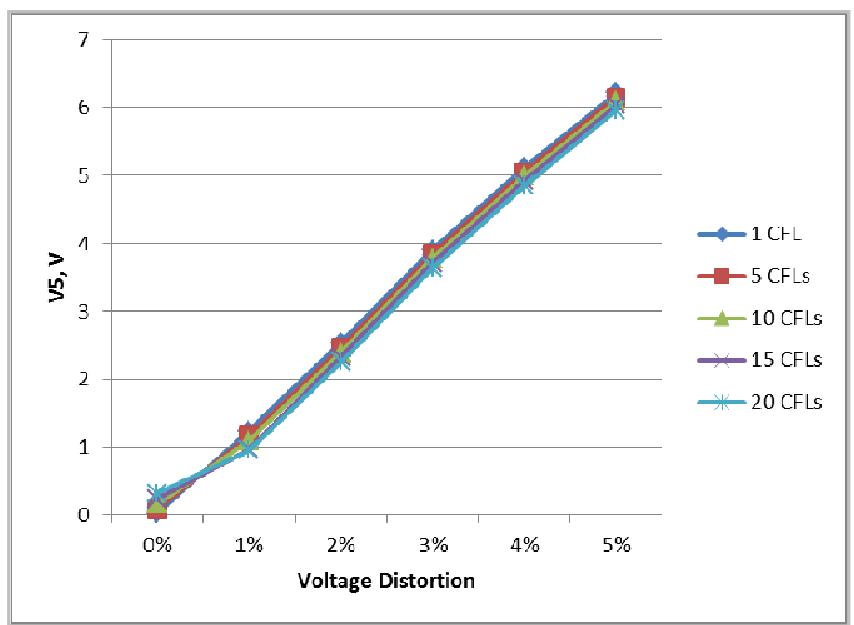

Figure 11. $5^{\text {th }}$ harmonic voltages vs. background voltage distortion variation

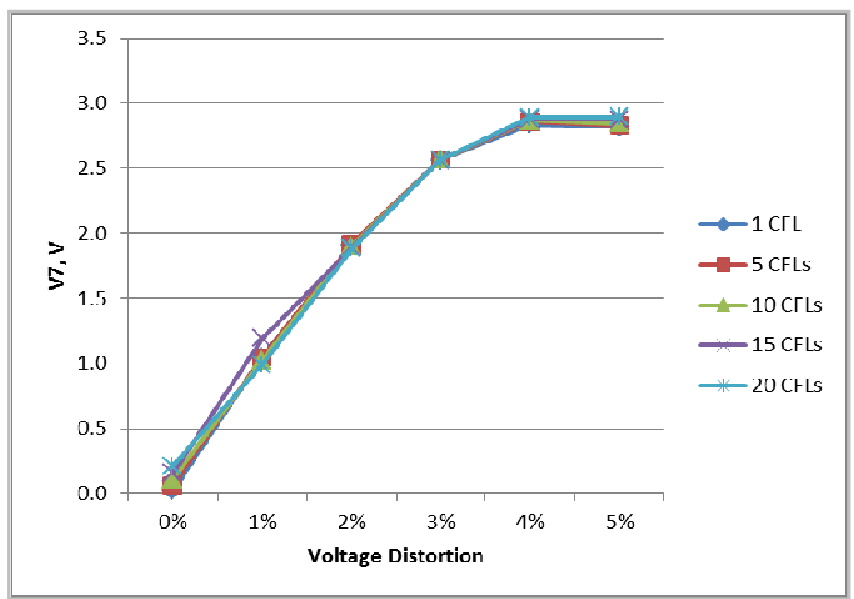

Figure 12. $7^{\text {th }}$ harmonic voltages vs. background voltage distortion variation

\section{Conclusion}

Power systems harmonics are continuously varying due to many factors. In this paper the impacts of source voltage, impedance, frequency and background voltage distortion variation on the harmonics generated from a group of CFLs have been evaluated for the normal variation of parameters within a power supply. Although system voltage, impedance $\mathrm{X} / \mathrm{R}$ ratio and frequency affect these harmonics slightly, system impedance magnitude has a very minor impact on the produced harmonics.

Notwithstanding, the background voltage distortion affects $\mathrm{THD}_{\mathrm{i}}, \mathrm{THD}_{\mathrm{v}}$ and individual harmonic currents and voltages significantly when the background voltage distortion varies within the IEEE 519 recommended limits. Individual harmonic currents tend to behave differently with increasing the background voltage distortion as the $3^{\text {rd }}$ harmonic currents decrease, $5^{\text {th }}$ harmonic currents decrease then increase whereas the $7^{\text {th }}$ harmonic currents increase.

Moreover, these factors are not isolated from each other. Rather, they occur simultaneously and their accumulative effects can be effectively high or some kind of harmonic compensation may occur.

\section{Acknowledgment}

The authors would like to acknowledge King Abdulaziz University for their financial support of this PhD study.

\section{References}

[1] J. C. Das, "Power System Analysis: Short-Circuit Load Flow and Harmonics", Marcel Dekker, 2002.

[2] E. F. Fuchs and M. A. S. Masoum "Power Quality in Power Systems and Electrical Machines", Academic Press, 2008.

[3] B. W. Kennedy, "Power Quality Primer", McGraw-Hill, New York, 2000.

[4] F. C. De La Rosa, "Harmonics and Power Systems", CRC Press, 2006.

[5] N. Mohan, T. M. Undeland, and W. P. Robbins, "Power Electronics: Converters, Applications and Design", 3rd ed., New York: John Wiley \& Sons, 2003.

[6] R. C. Dugan, M. F. McGranaghan, S. Santoso, and H. Wayne Beaty, "Electrical Power System Quality", McGraw-Hill Professional, 3rd ed., 2012.

[7] A. Ghosh and G. Ledwich, "Power Quality Enhancement Using Custom Power Devices", Kluwer Academic, Dordrecht, 2002.

[8] Shrivastava, A.; Singh, B.; , "PFC Cuk converter based electronic ballast for an $18 \mathrm{~W}$ compact fluorescent lamp," Industrial and Information Systems (ICIIS), 2010 International Conference on , vol., no., pp.393-397, July 29 2010-Aug. 1 2010.

[9] Lam, J.C.W.; Jain, P.K.; , "A High-Power-Factor Single-Stage Single-Switch Electronic Ballast for Compact Fluorescent Lamps," Power Electronics, IEEE Transactions on , vol.25, no.8, pp.2045-2058, Aug. 2010.

[10] Wei Yan; Tam, E.; Hui, S.Y.; , "A Semi-Theoretical Fluorescent Lamp Model for Time-Domain Transient and Steady-State Simulations," Power Electronics, IEEE Transactions on , vol.22, no.6, pp.2106-2115, Nov. 2007. 
[11] "Guidance on current and forth coming legislation within the lighting sector,": The Institution of Lighting Professionals, 2011.

[12] Ying-Chun Chuang; Chin-Sien Moo; Hsien-Wen Chen; Tsai-Fu Lin; , "A Novel Single-Stage High-Power-Factor Electronic Ballast With Boost Topology for Multiple Fluorescent Lamps," Industry Applications, IEEE Transactions on , vol.45, no.1, pp.323-331, Jan.-feb. 2009.

[13] Jing Yong; Liang Chen; Nassif, A.B.; Wilsun Xu; "A Frequency-Domain Harmonic Model for Compact Fluorescent Lamps," Power Delivery, IEEE Transactions on , vol.25, no.2, pp.1182-1189, April 2010

[14] Cunill-Sola, J.; Salichs, M.; , "Study and Characterization of Waveforms From Low-Watt ( 25 W) Compact Fluorescent Lamps With Electronic Ballasts," Power Delivery, IEEE Transactions on, vol.22, no.4, pp.2305-2311, Oct. 2007.

[15] Ying-Chun Chuang; Hung-Liang Cheng; , "Single-Stage Single-Switch High-Power-Factor Electronic Ballast for Fluorescent Lamps," Industrial and Commercial Power Systems Technical Conference, 2006 IEEE , vol., no., pp.1-7, $0-00$.

[16] A. Mansoor, W. M. Grady, A. H. Chowdhury, and M. J. Samotyj, "An investigation of harmonics attenuation and diversity among distributed single-phase power electronics loads," IEEE Trans. Power Delivery, vol. 10, pp. 467-473, Jan. 1995.

[17] A. Mansoor, W. M. Grady, P. T. Staats, R. S. Thallam, M. T. Doyle, and M. J. Samotyj, "Predicting the net harmonic currents produced by large numbers of distributed single-phase computer loads," IEEE Trans. Power Delivery, vol. 10, pp. 2001-2006, Oct. 1995.

[18] P. J. Moore and I.E. Portugués, "The influence of personal computer processing modes on line current harmonics", IEEE Transactions on power delivery, vol. 18, no. 4, October 2003.

[19] A. I. Maswood and J. Zhu, "Attenuation and Diversity Effect in Harmonic Current Propagation Study”, Proc. 2003 IEEE Power Engineering Society (PES) General Meeting, Toronto, Canada, 2003.

[20] Nassif, A.B.; Acharya, J., "An investigation on the harmonic attenuation effect of modern compact fluorescent lamps," Harmonics and Quality of Power, 2008. ICHQP 2008. 13th International Conference on, vol., no., pp.1-6, Sept. 28 2008-Oct. 12008.

[21] Nassif, A.B.; Wilsun $\mathrm{Xu}$; "Characterizing the Harmonic Attenuation Effect of Compact Fluorescent Lamps," Power Delivery, IEEE Transactions on , vol.24, no.3, pp.1748-1749, July 2009.

[22] Nassif, A.B, "Modeling, Measurement and Mitigation of Power System Harmonics", PhD Thesis, University of Alberta, 2009.

[23] S. Hansen, P. Nielsen, and F. Blaabjerg, "Harmonic cancellation by mixing nonlinear single-phase and three-phase loads" IEEE Trans. Ind. Applicat., vol. 36, pp. 152-159, Jan./Feb. 2000.

[24] W. M. Grady, A. Mansoor, E. F. Fuchs, P. Verde and M. Doyle, "Estimating the Net Harmonic Currents Produced by Selected Distributed Single-Phase Loads: Computers, Televisions, and Incandescent Light Dimmers", Power Engineering Society, Winter Meeting, IEEE, 2, 1090-1094, 2002.
[25] A. Mansoor, A.; Grady, W.M.; Thallam, R.S.; Doyle, M.T.; Krein, S.D.; Samotyj, M.J.; , "Effect of supply voltage harmonics on the input current of single-phase diode bridge rectifier loads," Power Delivery, IEEE Transactions on , vol.10, no.3, pp.1416-1422, Jul 1995.

[26] Paulo F. Ribeiro, "Time-varying waveform distortions in power systems", John Wiley \& Sons, 2009.

[27] M. H. J. Bollen And I. Y. H. Gu, "Signal Processing of Power Quality Disturbances", John Wiley \& Sons, 2006.

[28] Blanco, A.M.; Stiegler, R.; Meyer, J., "Power quality disturbances caused by modern lighting equipment (CFL and LED)," PowerTech (POWERTECH), 2013 IEEE Grenoble, vol., no., pp.1,6, 16-20 June 2013.

[29] Prudenzi, A.; Grasselli, U.; Lamedica, R., "IEC Std. 61000-3-2 harmonic current emission limits in practical systems: need of considering loading level and attenuation effects," Power Engineering Society Summer Meeting, 2001, vol.1, no., pp.277, 282 vol.1, 2001.

[30] Rawa, M.J.H.; Thomas, D.W.P.; Sumner, M.; Chin, J.X., "Source voltage, frequency and impedance variation effects on the harmonics generated from a Personal Computer," Power Electronics, Machines and Drives (PEMD 2012), 6th IET International Conference on , vol., no., pp.1,6, 27-29 March 2012 doi: 10.1049/cp.2012.0210.

[31] Rawa, M.J.H.; Thomas, D.W.P.; Sumner, M., "Harmonics attenuation of nonlinear loads due to linear loads," Electromagnetic Compatibility (APEMC), 2012 Asia-Pacific Symposium on , vol., no., pp.829,832, 21-24 May 2012.

[32] Rawa, M.J.H.; Thomas, D.W.P.; Sumner, M., "Factors affecting the harmonics generated by a cluster of personal computers," Harmonics and Quality of Power (ICHQP), 2014 IEEE 16th International Conference on, vol., no., pp.167, 171, 25-28 May 2014.

[33] Rawa, M.J.H.; Thomas, D.W.P.; Sumner, M., "Background voltage distortion and percentage of nonlinear load impacts on the harmonics produced by a group of Personal Computers," Electromagnetic Compatibility (EMC Europe), 2014 International Symposium on , vol., no., pp. 626,630, 1-4 Sept. 2014.

[34] Programmable AC Source 61511/61512 User's Manual (Chroma), Chroma ATE INC., Version 1.1, 2009, P/N A11 001293.

[35] PPA1500 KinetiQ User Manual, Newtons4th Ltd, 2010.

[36] IEEE Standard 519-1992, "IEEE Recommended Practices and Requirements for Harmonic Control in Electrical Power Systems".

[37] BS 7671:2008+A1:2011, "Requirements for electrical installations". IET Wiring Regulations. 7th edition.

[38] The Grid Code, N. G. E. T. plc, CC.6.1.2, (2011).

[39] (31 August 2011). Central Networks Supply Information. Available: http://www.eonuk.com/distribution/electricians.aspx

[40] "IEEE Standard Definitions for the Measurement of Electric Power Quantities Under Sinusoidal, Nonsinusoidal, Balanced, or Unbalanced Conditions," IEEE Std 1459-2010 (Revision of IEEE Std 1459-2000), volume, no., pp.1-40, March 19 (2010). 
[41] Lam, J.C.W.; Jain, P.K.; Jain, P.K.; , "A Dimmable Electronic Ballast With Unity Power Factor Based on a Single-Stage Current-Fed Resonant Inverter," Power Electronics, IEEE Transactions on , vol.23, no.6, pp.3103-3115, Nov. 2008.
[42] Chan, S. S. M.; Chung, H. S.-H.; Lee, Y.-S.; "Design and Implementation of Dimmable Electronic Ballast Based on Integrated Inductor," Power Electronics, IEEE Transactions on, vol.22, no.1, pp.291-300, Jan. 2007.

[43] Chang-Shien Lin;, "Low power $60 \mathrm{kHz}$ electrodeless fluorescent lamp for indoor use," IPEC, 2010 Conference Proceedings, vol., no., pp.682-686, 27-29 Oct. 2010. 